\title{
Careers and Survival: competition and risk in the hedge fund and CTA industry
}

\author{
Stephen J. Brown, NYU Stern School of Business \\ William N. Goetzmann, Yale School of Management \\ James Park, PARADIGM Capital Management, Inc.
}

October 29, 2000

\begin{abstract}
Investors in hedge funds and commodity trading advisors [CTA's] are naturally concerned with risk as well as return. In this paper, we investigate risk of hedge funds and CTA's in light of managerial career concerns. We find an association between past performance and risk levels consistent with Brown, Harlow and Starks (1996) findings for mutual fund managers. Good performers in the first half of the year reduce the volatility of their portfolios, and poor performers increase volatility. These "variance strategies" depend upon the fund's ranking relative to other funds. The importance of relative rankings as opposed to the absolute ranking suggested by analysis of hedge fund and CTA manager contracts points to the importance of reputation costs. These costs are best thought of in the context of the career concerns of managers and the relative importance of fund termination. We analyze factors contributing to fund disappearance. Survival depends on both absolute and relative performance. Excess volatility can also lead to termination. Finally, other things equal, the younger a fund, the more likely it is to disappear from the sample. Therefore our results strongly confirm an hypothesis of Fung and Hsieh (1997b) that reputation costs have a mitigating effect on the gambling incentives implied by the manager contract. Particularly for young funds, a volatility strategy that increases the value of a performance fee option may lead to the premature death of that option through termination of the fund. The finding that hedge fund and CTA volatility is conditional upon past performance has implications for investors, lenders and regulators. An important result of our finding is that variance strategy depends upon relative rather than absolute
\end{abstract}

Acknowledgements: The authors thank TASS for providing their data for analysis. We thank David Hsieh for his encouragement with the project, Carl Ackerman, Jennifer Carpenter, Ian Domowitz and Steven Heston for their helpful comments, and both Markus Karr and Jeremy Staum for able assistance programming and in preparation of the data. In addition, we acknowledge the contributions of participants at presentations at a December 1997 CBOT conference, the 1999 American Finance Association meetings, the 1999 Asia Pacific Finance Conference, and at seminars given at the University of Colorado Burridge Center, Carnegie Mellon University, International University of Japan, University of Notre Dame, New York Federal Reserve Bank, and Pennsylvania State University. All errors are the sole responsibility of the authors. 
performance evaluation. 


\section{Introduction}

Hedge funds and commodity trading advisors [CTAs] are curiosities in the investment management industry. Unlike mutual funds and most pension fund managers, they have contracts that specify a dramatically asymmetric reward. Hedge fund managers and commodity trading advisors are both compensated with contracts that pay a fixed percentage of assets and a fraction of returns above a benchmark of the treasury bill rate or zero. In addition, most of these contracts contain a "high water mark" provision that requires the manager to make up past deficits before earning the incentive portion of the fee. These contract provisions would suggest that hedge fund managers have a strong incentive to take on extreme risk, particularly when their incentive contract is out of the money. The interesting fact is that they do not behave as this simple theory would suggest. We find that excess risk and poor relative performance increase substantially the probability of termination, and that this represents a reputation cost sufficient to offset the adverse gambling incentive of the high watermark contract. An important result of our finding is that variance strategy depends upon relative rather than absolute performance evaluation. Our evidence on "relative performance" competition among managers in the hedge fund industry sheds light on factors influencing managerial careers. The need to beat the pack, rather than beating a fixed benchmark appears to influence management risk choice. Risk choice, in turn has an effect on future survival.

Goetzmann, Ingersoll and Ross (1997), Grinblatt and Titman (1989) and Carpenter (2000) all show analytically that the value of the manager's contract is increasing in portfolio variance due to the call-like feature of the incentive contract. Thus, when the incentive contract is out-of-the-money, managers have a strong incentive to increase variance. On the other hand, 
as Fung and Hsieh (1997b) show, reputational concerns and contractual constraints may mitigate or prevent such behavior. There is a clear tension between risk-taking and the desire to preserve or develop a reputation once the reputation has been developed.

Prospects for future employment within a firm and within the industry are undoubtably a strong motivator. We have collected data on individual managers active in the offshore fund industry over the period 1989 through 1995. The data represent a large fraction of the major hedge fund managers and large hedge funds during the period. We are able to explore in some detail how frequently managers are fired in the hedge fund industry, and also their potential for re-employment following firing. We find that, once a manager drops from our sample the chances or re-appearing as a money manager are very small. This sends support to the idea that the threat of firing is a major one.

The extent to which reputational issues relate to or offset the incentives to gamble is in the end an empirical issue. We use technology developed by Brown Harlow and Starks (1995) [BHS] to address this. BHS present strong evidence on mutual fund variance strategies, although their work is limited to managers compensated by fixed or at best symmetric compensation plans. While fund managers may be paid performance bonuses, mutual funds are not permitted to charge asymmetric fees. On the other hand, hedge funds and CTAs are - thus, our data allows us to examine the variance strategies of managers compensated asymmetrically. Our results are on the surface puzzling — despite major differences in the form of manager compensation, we find little difference between the behavior of hedge fund/CTA managers and mutual fund managers. We identify a significant reduction in variance conditional upon having performed well and limited evidence that managers who perform less well increase their risk exposure. 
However, we find little or no evidence that poor performers who survive increase volatility to meet their high water mark.

To examine the issue of how the variance strategy interacts with the high water mark threshold, we examine whether manager strategies are conditional upon absolute versus relative performance cutoffs. While the high water mark contract is designed to induce behavior conditional upon absolute performance, in fact we find evidence that the variance strategy depends on relative performance. These variance strategies do not depend at all on absolute performance despite the popular perception that hedge fund managers are market neutral and care only about absolute performance ${ }^{1}$.

The fact that variance strategies depend on relative but not absolute performance suggests that reputation costs, or institutional constraints proxying for them, indeed play a significant role in modifying incentives to take risk. Although there is little in the high water mark contract to explicitly penalize poorly performing managers there are great implicit costs to taking risks that might lead to termination. To pursue this matter further, we examine the factors associated with funds and managers exiting the industry. Negative returns over one year and two year horizons increase the likelihood of fund termination. However, even controlling for this, relative returns and volatility also play a significant role. The younger the fund, other things equal, the more likely it is to be terminated. Our survival analysis suggests that CTAs and hedge fund managers are seriously concerned with closure, as opposed to maximizing the option-like feature of their contract.

Our findings have implications for investors, lenders and regulators. If hedge fund and CTA risk depends upon relative performance, then investors and lenders can adjust their 
exposure to such risk accordingly. Our negative findings regarding risk-taking conditional upon poor absolute performance should be valuable to regulators concerned with preparing for worstcase scenarios.

This paper is structured as follows. The next section provides the institutional context for the career concerns of managers in the hedge fund industry. The third section discusses the data. Section four reports the results of our empirical analysis, section five considers the causes of fund attrition in detail and section six concludes.

\section{Industry Structure and Manager Careers}

Chevalier and Ellison (1997) show that career concerns of mutual fund managers play a significant role in their decision about risk. They show that fund managers are frequently terminated (or quit) and they frequently re-appear later, managing other funds. Both the systematic and the unsystematic risk they choose for their fund appear to impact their future ability to secure employment in the industry. We would expect similar concerns among hedge fund managers, however the nature of the hedge fund industry differs from that of the mutual fund industry in ways that could potentially affect manager risk choice. Not only are manager contracts asymmetric in the payoffs, but the ability of a manager to raise additional money or start another fund in the future is likely to be as important as whether he is fired as a manager. In the section that follows, we describe the general nature of the hedge fund manager contract.

Hedge funds are managed by one or more individuals who aggregate money from accounts and invest them in securities. The principal feature distinguishing a hedge fund from a mutual fund is that is does not conform to the standards established under the Investment 
Company Act of 1940. By not conforming to the range of standards in the act, hedge funds are prevented from public offering of their services. Until 1996, investment companies that did not conform to the requirements for open or closed-end mutual fund status were prevented from having than 99 U.S. investors. In 1996, this limitation was raised to 499, however investors were required to demonstrate a level of sophistication that certified they understood the risks involved. The importance of this distinction for the current study is that hedge fund managers cannot easily and widely market their services. Constraints on the number of accounts means that managers must focus on a select number of potential clients. Because of the limits on numbers of accounts, no client is atomistic -- the threat of withdrawal is important and the potential for communication among a few large clients cannot be discounted. This threat helps understand the two basic types of hedge funds -- single manager and multiple manager funds. Single manager funds offer the services of one manager with his or her own management style and track record. Multiple manager funds, also called fund-of-funds, are investment pools that holds shares in a number of single manager funds and charges a fee for selecting or providing access to those funds. The role of a fund of funds is thus not only to cull managers with superior ability. It also provides smaller investors access to major single-manager funds which otherwise might be closed to outside investment as a result of the numerical limitation on accounts. Conversely, the fund of fund is an intermediary that provides investment capital to managers who otherwise may not have access to investors due to SEC restrictions on the marketing of their services. Because funds may retain more than one manager and managers may work for more than one fund, a fund manager's career is best characterized by a time-series of annual engagements by one or more funds. Even when a fund closes or drops a manager, that manager 
may continue to work in the industry as a manager of another fund. Survival in the industry means retaining at least one engagement. In the analysis below, we use a database of annual manager engagements to examine the survival rate of managers. The database allows us to consider the factors that may impact the career concerns of hedge fund managers -- particularly concerns about disappearing from the business.

\section{II.2 Manager data}

We collected data on 715 hedge fund managers who were associated from 1989 through 1995 with offshore funds listed in the Offshore Funds Directory, [OFD] an annual compendium of Offshore funds performance. The OFD is unusual in that is is published each year and allows concrete verification that the data are not backfilled. The problems of survival conditioning and backfilling of hedge fund data bases is now well known. While offshore funds are a sub-sample of hedge funds, they are a sub-sample of major players in the industry. Most of the major hedge funds during this period had offshore vehicles for investment. The database is used in Brown, Goetzmann and Ibbotson (1999) to analyze the performance of edge funds as an asset class. In the current paper, however, we focus explicitly on managers, their compensation and their career trajectories. The database helps to understand the apparent paradox of managers failure to maximize the value of an option.

Of the 715 managers that appeared in the database over the seven year period, we identified 2,221 separate engagement-years. An engagement for a manager is an employment

contract with a single fund. An engagement-year is one completed year of this contract. Our of 715 managers, 278 disappeared from the sample before the final year 1995 . We found 373 
disengagements from funds in the sample and of these, 322 resulted in the manager disappearing from the sample, while 51 of these disengagements resulted in the manager dropping to a lower number of engagements. Most striking in the database is the inability of managers to re-appear in the database after dropping out. We found only five instances of a manager re-appearing. Our enumeration of manager disengagements suggests that there is a significant attrition rate for managers, that disengagements typically mean disappearance and reappearance is rare. All of these point to the desirability of avoiding disengagement.

\section{Available fund data}

TASS is a New York-based advisory and information service that maintains a large database of CTA and hedge fund managers that we used in this analysis. This TASS data is used in recent research by Fung and Hsieh (1997a\&b). A competitor to TASS, Managed Account Reports (MAR) has data on both manager populations as well, and this is the data used by Ackerman, McEnally and Ravenscraft (1999) and Park (1995)². Neither of these two sources is a "follow-forward" database of the kind used in BGI. Consequently we could not verify the extent to which defunct funds have been dropped from the sample until very recently. TASS has recognized the importance of maintaining defunct funds in their data, and since 1994 they have kept records of hedge funds that cease to operate. Fung and Hsieh (1997b) find evidence that the survival bias in the TASS CTA returns is more than $3 \%$ per year. Because of the limited coverage of the database before 1988, we use TASS data for the period 1989-98 in our study. We have augmented this database by hand collecting missing data, and by using information provided by Daniel B. Stark \& Co., Inc. for CTA data not covered by TASS. Table 1 contains a 
count of the funds in this augmented database.

Survival is not the only potential conditioning in the data. Park's (1995) analysis of the MAR data suggests that funds are typically brought into the database with a history. This conditioning has two separate implications. First, a fund might be brought in because the manager has chosen to report a good track record -- i.e., self-selection bias. Second, a survival bias is imparted because having a two-year or more track record implies that the fund survived for two years, while others with similar characteristics failed. Ackermann, McEnally and Ravenscraft(1999) have an extensive analysis of these different sources of bias in a similar hedge fund sample. ${ }^{3}$ Table 1 reports the time-series counts of CTAs and hedge funds. Notice that survival is an important issue for TASS' CTAs — roughly $20 \%$ disappear per year since 1990. The $20 \%$ attrition rate for CTAs is consistent with the numbers in BGI for offshore hedge funds. The attrition rates for the TASS hedge funds are suspiciously lower — less than $15 \%$ per year since 1994. However, the half life of the TASS hedge funds is exactly 30 months (Figure 1), which corresponds to the offshore hedge fund results reported by BGI. CTA funds have a shorter half life of only two years.

Recent evidence suggests that both single-period and multi-period conditioning implies that analysis of surviving fund returns can lead to false inferences ${ }^{4}$. Evidence suggests that multi-period conditioning is indeed a feature of this industry. Therefore it seems likely that the statistical analysis of both of these databases is likely to be biased. Fortunately, the direction of at least some of these biases are well understood and will be discussed further in Section IV.

\section{Volatility Strategies}




\section{IV.1 Sorts by Deciles}

Following BHS, we test whether fund performance in one period explains the change in variance of fund returns in the following period. Figures 2 and 3 show the simplest form of this test for CTAs and hedge funds. For each year in the sample, we compute performance deciles based on January through June total return. We then compute monthly returns in excess of style benchmarks ${ }^{5}$ and calculate the variance of excess returns for the period January-June and JulyDecember. The ratio of these two numbers is then a measure of the extent to which fund managers increase volatility in the course of the year. The figures plot the median variance ratio by performance decile. They show clear evidence that funds that do exceptionally well in the first half of the year reduce variance. This is true for both hedge funds (Figure 2) and CTAs (Figure 3). In both cases the reduction in volatility is most significant in the highest decile of performance. In addition, hedge funds and CTAs that perform worse than the median manager increase variance.

A simple explanation for this pattern of variance changes is that funds adopt a passive leverage policy. Most of the funds in the sample use a substantial amount of leverage. Passive leverage is one possible explanation for the very high leverage ratios reported for Long-Term Capital Management in September 1998. As the asset value of the fund fell, borrowing was constant. The further the fund fell in value, the higher was its leverage and consequent volatility. As the value of the fund rose again, leverage fell and so too did volatility. To test this theory, we divided the sample up into those who lost money, and those who gained during the first six months. The average leverage for the first group will have risen and the average leverage for the second group will have fallen over the sample period. The passive leverage hypothesis would 
predict that the first group will experience a rise in volatility, with the greatest rise among those funds whose loss in the second period was greater than the loss in the first period. The same hypothesis would predict that the funds that made money in the first six months will experience a fall in volatility. The largest decrease in volatility will occur among those funds whose return July through December exceeds the positive return in the first half of the year. Neither implication is supported in the data ${ }^{6}$.

It is also important to consider active constraints on leverage that may be imposed by lenders. Credit may be suspended after extreme performance. Lenders may not give the poor performers the resources to take larger risks, even if the manager wanted to do so. This would tend to offset the leverage effect, making it more difficult to reject the null hypothesis that managers seek to "double-down." The experience of 1998 shows that funds who do really poorly may be forced by lenders to liquidate assets to pay down debt. There thus may be limits to the passive leverage effects. The may help explain the results we find for extreme performers. While poor performers do increase variance, we find that the greatest increase in volatility occurs among the median performers, rather than among the worst performers. The increase in volatility among the poor performers is only marginally significant. Given that the manager's incentive is essentially a call option with exercise price determined by the high water mark provision, one would expect a rational manager to increase the value of this out-of-the-money option by increasing variance ${ }^{7}$. Indeed, this is the classic moral hazard problem induced by asymmetric incentives. Given that $20 \%$ of CTA managers disappear each year since 1990, any fund in the lowest decile may have a reasonably high probability of disappearance. Any manager who judges his or her likelihood of disappearance at mid year as a virtual certainty has a powerful 
incentive to "double down" by taking much higher risks. Clearly, another factor must be at work that persuades poorly performing managers to limit any increase in volatility.

One conjecture discussed above is that lenders will not let them take on more risk. Fung and Hsieh (1997b) examine a closely related conjecture about extreme poor performers, which they term an "end-game" strategy. They offer another hypothesis that may explain why poor performers do not "double down." They look at firms that are likely to go out of business. Those that are part of a multi-fund firm, they assert, will be less likely to take big risks when they are down, and more likely to be shut down before doing really poorly. This is because a poor performer makes the whole firm look bad. In fact, they find that CTA funds in multi-manager firms do relatively better, and take less systematic risk -- both consistent with the hypothesis that there are reputational externalities that may prevent big gambles. Our results appear to provide support for this hypothesis as well as the lender constraint story. In one case the enforcement mechanism is conditional bank control. In the other, reputation concerns proxy for external control.

\section{IV.2 Contingency Table Tests}

Table 2 tests the significance of the strategic use of variance by the funds in our sample. These results are exactly conformable with similar results reported by BHS for a six-month comparison period. Results broken down by CTAs and hedge funds exhibited the same patten. This period represents half of the normal annual reporting period for hedge funds and CTAs. If we define high return funds as funds whose six month return is in excess of that of the median fund, we find on a year by year basis that high return funds decrease variance while low return 
funds increase variance. This is true nine years out of ten for the whole sample, eight years out of ten for CTAs and five out of ten for hedge fund. The pattern is statistically significant for all years taken together. The reversals of pattern are small in number and in any event are not statistically significant. The magnitude of these numbers matches the numbers reported on a similar basis by BHS.

These results seem to suggest that poor performers do indeed increase the volatility of their funds as a strategic response to the nature of their performance incentive contract. Taken at face value, it would appear that the managers are responding to the fact that their options are out of the money by increasing variance. However, this hypothesis is not correct. The second panel of the table examines the strategic response to whether the performance fee options are in or out of the money ${ }^{8}$. Here we find a very different picture. Not only do we fail to find that losers increase volatility and winners decrease volatility. Sometimes, losers actually decrease volatility, and winners increase volatility. In any event, the strategic volatility pattern is significant in only one year (1990) for each of the fund groupings, and is insignificant over all. Evidently, performance relative to other funds is important, while performance relative to the high water mark is not.

Is this pattern induced by survival? Simulations approximating these strategic variance tests are reported in Brown, Goetzmann, Ibbotson and Ross (1997). We show that a 10\% performance cut on the first period, corresponding to the elimination of the worst decile of performers would induce a "J" shape response of variance to returns. To the extent that the strategic variance effect is a reduction of variance by winners, the simulations in the BGIR 97 article would bias the test towards type II error. In addition, survival arguments would suggest 
that winners would ex post display an increase in variance 9 . Thus, we do not believe the results are due to conditioning upon survival over the year-long period.

\section{Survival and Relative Performance}

While the high-water-mark contract is designed to induce behavior conditional upon absolute performance, the results in Figures 2 and 3, and Table 2 provides evidence that managers pay more attention to their performance relative to the rest of the industry. This is despite the popular perception that hedge fund managers are market neutral and care only about absolute performance. The results of the previous section clearly show that survival is at least as important as a single-year performance tournament. The management incentive fee option expires on termination of the fund. Thus, any attempt to maximize a single-period fee option represents a trade-off against risking the termination of the option value at the end of the period. What role does performance and risk play in fund termination? We address this question empirically in this section.

Table 3 reports the results from two kinds of analysis that support the contention that both relative and absolute performance over multiple periods play a role in fund termination. Relative performance is defined by the risk-adjusted performance (i.e. the alpha) of the fund manager. This is similar to the relative performance measure in the previous table, with the additional adjustment for systematic risk exposure. Absolute performance in the table is captured by an indicator of whether the fund experienced positive returns in the previous periods. Funds with negative returns are those which are falling farther out of the money with respect to their high water mark provisions. 
Besides performance, volatility and seasoning are also important factors to include in the estimation. For every quarter end from December 1989 (December 1993 for hedge funds) we record the one quarter, one year and two year performance characteristics, volatility and seasoning. We then record whether the fund survives the following quarter and perform a standard Probit analysis of fund termination. The results are reported in the first panel of Table 3.

For CTA funds, poor absolute performance over both a one year and a two year holding period basis significantly increase the probability of fund termination. This is consistent with a view that fund managers voluntarily terminate funds where there is no reasonable possibility of meeting an increasing high water mark provision in the incentive contract. However, short term relative performance and volatility also play a role. This suggests that not increasing volatility may be quite rational for managers already at risk because of poor performance. The increase in volatility may increase the chance of the incentive contract ending up in the money, but may of itself increase the probability of termination and poor short term returns that would also contribute to termination.

Seasoning appears to play a role in fund survival. This is consistent with the results of Chevalier and Ellison (1999) who find that more seasoned managers are less concerned with termination. We find that the longer the fund has been in existence, the more likely it is to survive. The role of seasoning bears closer examination. In a recent paper, Lunde, Timmermann and Blake (1999) argue persuasively that a Probit analysis is too restrictive. It requires not only strong distributional assumptions, but also strong parametric assumptions about the role of seasoning in the survival of funds. They argue for a semi parametric Cox hazard rate regression approach. Applying this to the data yields almost precisely the same answers as the Probit 
analysis. It confirms that our results are robust to the way we have modeled survival.

It is interesting to compare CTA results and hedge fund results. While most of the results are similar across the two fund groups, they differ in three important respects. While short term poor performance is less important for hedge funds, hedge funds are more likely to be terminated if they have poor relative performance measured on an annual basis. The Investment Company Act of 1940 imposes important restrictions on the distribution of information about hedge funds, whereas CFTC regulation implies that CTA clients have access to reliable and timely information to evaluate relative performance. This is at least a partial explanation for the relative importance of short term performance information for CTAs. The same argument may explain why it is that avoiding excess volatility is far more critical for hedge fund survival than for CTAs. Other things equal, the more risk a hedge fund takes on, the less likely it is to survive. The final and most important difference in the hedge fund manager results is the influence of volatility on disappearance. We find strong evidence that higher risk is a factor in the termination of the fund. After controlling for relative performance, seasoning and volatility, hedge funds are increasingly more likely to be terminated. The relationship between volatility and termination provides a disincentive for hedge fund managers to gamble excessively when they fall below their high water mark. While one might expect that termination and risk-taking is may be a Long-Term Capital Management spillover effect, it appears to have been evident before the well-publicized problems of that particular hedge fund. As such, it has likely been an important consideration in the career concerns of hedge fund managers since the beginning of the decade. 


\section{Conclusion}

Financial economists have long debated what kind of incentives may induce managers to take a longer view rather than to maximize short-term performance. In the investment industry it is possible for participants to observe, quantify and contract on performance. Hedge funds and CTA's typically have incentive contracts that asymmetrically compensate managers based on annual performance. In this setting, a single-period theoretical analysis might suggest that managers below their high water marks have a strong incentive to increase risk, irrespective of the performance of other managers in their industry. We find this not to be the case. The high water mark threshold has little effect on managerial choice of risk - manager risk choice appears more strongly motivated by industry benchmarks. We interpret this apparent contradiction to strong manager concerns about their future in the industry. The threat of termination is apparently a much stronger motivator than a single-year gain. Our data thus appears to evidence the kind of multi-period conditioning analyzed by Carpenter and Lynch (1999), suggesting that future modeling of the industry and of manager career concerns has to take into account long term performance effects. ${ }^{10}$

Applying a probit model to hedge fund and CTA industry data over a number of years, we find that fund termination is a function of performance relative to high water mark thresholds as well as industry benchmarks. The former suggests that managers shut down when they are too far from their strike price, and the latter suggests that investors deciding whether to withdraw funds may implicitly compare a fund performance its peers, even controlling for distance from the high water mark. Thus a fund lagging the industry is less likely to survive. Finally, we document the relationship between risk and survival and seasoning. We find that riskier funds 
are less likely to survive another year, and that older funds are less sensitive to performance. Taken together, our results imply that, despite the seeming moral hazard implicit in asymmetric performance contracts, the hedge fund and CTA industry provides s disincentives to the maximization of short-term profits through risk-taking - our results imply that survival in the industry is apparently too valuable. Despite widely publicized fund closures and restructurings over the past few years, there is little evidence that funds in the industry increase risk to take advantage of incentive contract terms - their risk-taking is more likely driven by peer performance and tempered by the strong relationship between volatility and termination. 


\section{References}

Ackerman, Carl, Richard McEnally and David Ravenscraft, 1999, "The performance of hedge funds: risk, return and incentives," Journal of Finance 54(3) 833-874

Brenner, Menachem and David Yermack, 2000, "Altering the Terms of Executive Stock Options," Journal of Financial Economics, forthcoming

Brown, Keith, Van Harlow and Laura Starks, 1996, "Of tournaments and temptations: an analysis of managerial incentives in the mutual fund industry," Journal of Finance 51(1), 85110.

Brown, Stephen and William Goetzmann, 1997, "Mutual Fund Styles." Journal of Financial Economics 431997 373-399

Brown, Stephen J., William N. Goetzmann and Roger G. Ibbotson, 1999, "Offshore hedge funds,: survival and performance, 1989 - 1995." Journal of Business, 72(1) 91-119. .

Brown, Stephen J., William N. Goetzmann, Roger G. Ibbotson and Stephen A Ross, 1992, "Survivorship Bias in Performance Studies," Review of Financial Studies, 5, 553-580.

Brown, Stephen J., William N. Goetzmann, Roger G. Ibbotson and Stephen A Ross, 2997, "Rejoinder: The J-shape of performance persistence given survivorship bias," Review of Economics and Statistics, 79. 167-170.

Carpenter, Jennifer, 2000, "The optimal investment policy for a fund manager compensated with an incentive fee," Journal of Finance forthcoming

Carpenter, Jennifer, and Anthony Lynch 1999, "Survivorship bias and reversals in mutual fund performance," Journal of Financial Economics, 54(3) December 337-74.

Carhart, Mark, 1997, "On Persistence in Mutual Fund Performance," Journal of Finance, 52: (1), March 1997, pages 57-82.

Chevalier, Judith and Glenn Ellison, 1997 "Risk taking by mutual funds as a response to incentives" Journal of Political Economy 114 389-432.

Chevalier, Judith and Glenn Ellison, 1999, "Career concerns of Mutual Fund Managers," The Quarterly Journal of Economics,114: (2), May, pages 389-432.

Fung, William and David Hsieh, 1997, "Empirical characteristics of dynamic trading strategies: the case of hedge funds," the Review of Financial Studies, 10,2, Summer, pp. 275-302. 
Fung, William and David Hsieh, 1997b, "Survivorship bias and investment style in the returns of CTAs: the information content of performance track records, " Journal of Portfolio Management, 24, 30-41.

Fung, William and David Hsieh, 2000, "Performance characteristics of hedge funds and CTA funds: Natural versus spurious biases," Journal of Financial and Quantitative Analysis forthcoming.

Goetzmann, William, Jonathan Ingersoll, Jr. and Stephen A. Ross, 1997, "High water marks," Yale School of Management Working Paper.

Greene, William, 1997, Econometric Analysis (Prentice Hall, New Jersey)

Grinblatt, Mark and Sheridan Titman, 1989, "Adverse risk Incentives and the design of performance-based contracts," Management Science, 35, 807-822.

Hendricks, Daryl, Jayendu Patel and Richard Zeckhauser, 1997, "The J-shape of performance persistence given survivorship bias," Review of Economics and Statistics, 79. 161-166.

Khorana, Ajay, 1996, "Top Management Turnover: An Empirical Investigation of Mutual Fund Managers," Journal of Financial Economics, 40. 403-427.

Liang, Bing, 2000, "Hedge Funds: The Living and the Dead," Journal of Financial and Quantitative Analysis, forthcoming

Lunde, Asger, Allan Timmermann and David Blake, 1999 "The hazards of underperformance: A Cox regression analysis," Journal of Empirical Finance, 6. 121-152.

Massa, Massimo, 1997, "Do investors react to mutual fund performance? An imperfect competition approach?" Yale University Department of Economics Working Paper.

Park, James M., 1995, "Managed futures as an investment asset," Doctoral dissertation, Columbia University.

Starks, Laura, 1987, "Performance incentive fees: an agency-theoretic approach," Journal of Financial and Quantitative Analysis, 22, 17-32. 
Table 1: Augmented TASS Database of CTAs and Funds

\begin{tabular}{|c|c|c|c|c|c|c|c|c|}
\hline & \multicolumn{4}{|c|}{ CTAs } & \multicolumn{4}{|c|}{ Hedge Funds } \\
\hline & $\begin{array}{c}\text { Total } \\
\text { Funds }\end{array}$ & $\begin{array}{l}\text { New } \\
\text { Funds }\end{array}$ & $\begin{array}{l}\text { Defunct } \\
\text { Funds }\end{array}$ & $\begin{array}{l}\text { Surviving } \\
\text { Funds }\end{array}$ & $\begin{array}{l}\text { Total } \\
\text { Funds }\end{array}$ & $\begin{array}{l}\text { New } \\
\text { Funds }\end{array}$ & $\begin{array}{l}\text { Defunct } \\
\text { Funds }\end{array}$ & $\begin{array}{l}\text { Surviving } \\
\text { Funds }\end{array}$ \\
\hline 1971 & 1 & 1 & 0 & 1 & & & & \\
\hline 1972 & 1 & 0 & 0 & 1 & & & & \\
\hline 1973 & 2 & 1 & 0 & 2 & & & & \\
\hline 1974 & 3 & 1 & 0 & 3 & & & & \\
\hline 1975 & 4 & 1 & 0 & 4 & & & & \\
\hline 1976 & 6 & 2 & 0 & 6 & & & & \\
\hline 1977 & 7 & 1 & 0 & 7 & 2 & 2 & 0 & 2 \\
\hline 1978 & 8 & 1 & 0 & 8 & 4 & 2 & 0 & 4 \\
\hline 1979 & 13 & 5 & 0 & 13 & 5 & 1 & 0 & 5 \\
\hline 1980 & 20 & 7 & 0 & 20 & 6 & 1 & 0 & 6 \\
\hline 1981 & 29 & 9 & 0 & 29 & 8 & 2 & 0 & 8 \\
\hline 1982 & 37 & 8 & 0 & 37 & 12 & 4 & 0 & 12 \\
\hline 1983 & 50 & 13 & 0 & 50 & 19 & 7 & 0 & 19 \\
\hline 1984 & 77 & 27 & 0 & 77 & 28 & 9 & 0 & 28 \\
\hline 1985 & 107 & 30 & 0 & 107 & 35 & 7 & 0 & 35 \\
\hline 1986 & 142 & 35 & 1 & 141 & 53 & 18 & 0 & 53 \\
\hline 1987 & 189 & 47 & 3 & 185 & 82 & 29 & 0 & 82 \\
\hline 1988 & 254 & 65 & 5 & 245 & 109 & 27 & 0 & 109 \\
\hline 1989 & 443 & 99 & 13 & 331 & 151 & 21 & 0 & 130 \\
\hline 1990 & 563 & 116 & 51 & 396 & 258 & 64 & 0 & 194 \\
\hline 1991 & 750 & 177 & 65 & 508 & 304 & 55 & 0 & 249 \\
\hline 1992 & 870 & 181 & 72 & 617 & 457 & 104 & 1 & 352 \\
\hline 1993 & 975 & 179 & 97 & 699 & 706 & 177 & 2 & 527 \\
\hline 1994 & 1055 & 178 & 132 & 745 & 877 & 175 & 16 & 686 \\
\hline 1995 & 1091 & 173 & 131 & 787 & 1096 & 205 & 57 & 834 \\
\hline 1996 & 1069 & 141 & 130 & 798 & 1290 & 228 & 110 & 952 \\
\hline 1997 & 1036 & 119 & 78 & 839 & 1410 & 229 & 110 & 1071 \\
\hline 1998 & 995 & 78 & 146 & 771 & 1411 & 170 & 168 & 1073 \\
\hline
\end{tabular}




\section{Survival of CTAs and Hedge Funds}

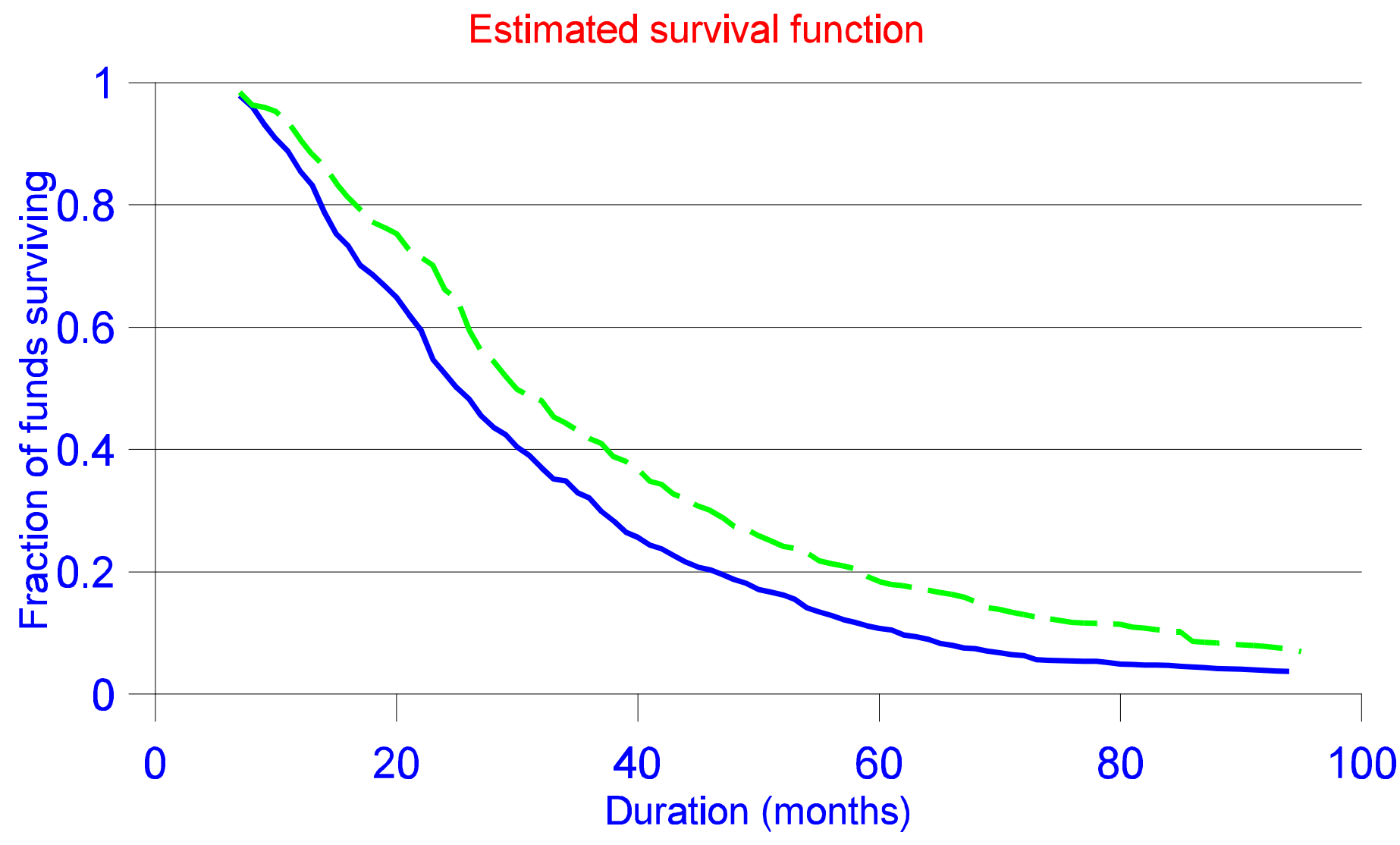

\section{CTAs}

Hedge Funds

Figure 1

This figure gives the fraction of funds alive after six months that survive in the database for the specified duration of time. This calculation excludes the CTA funds in the database prior to January 1989. We exclude hedge funds in the database prior to January 1994 on the grounds that data on the number of nonsurvivors prior to that date are nonexistent or unreliable. 


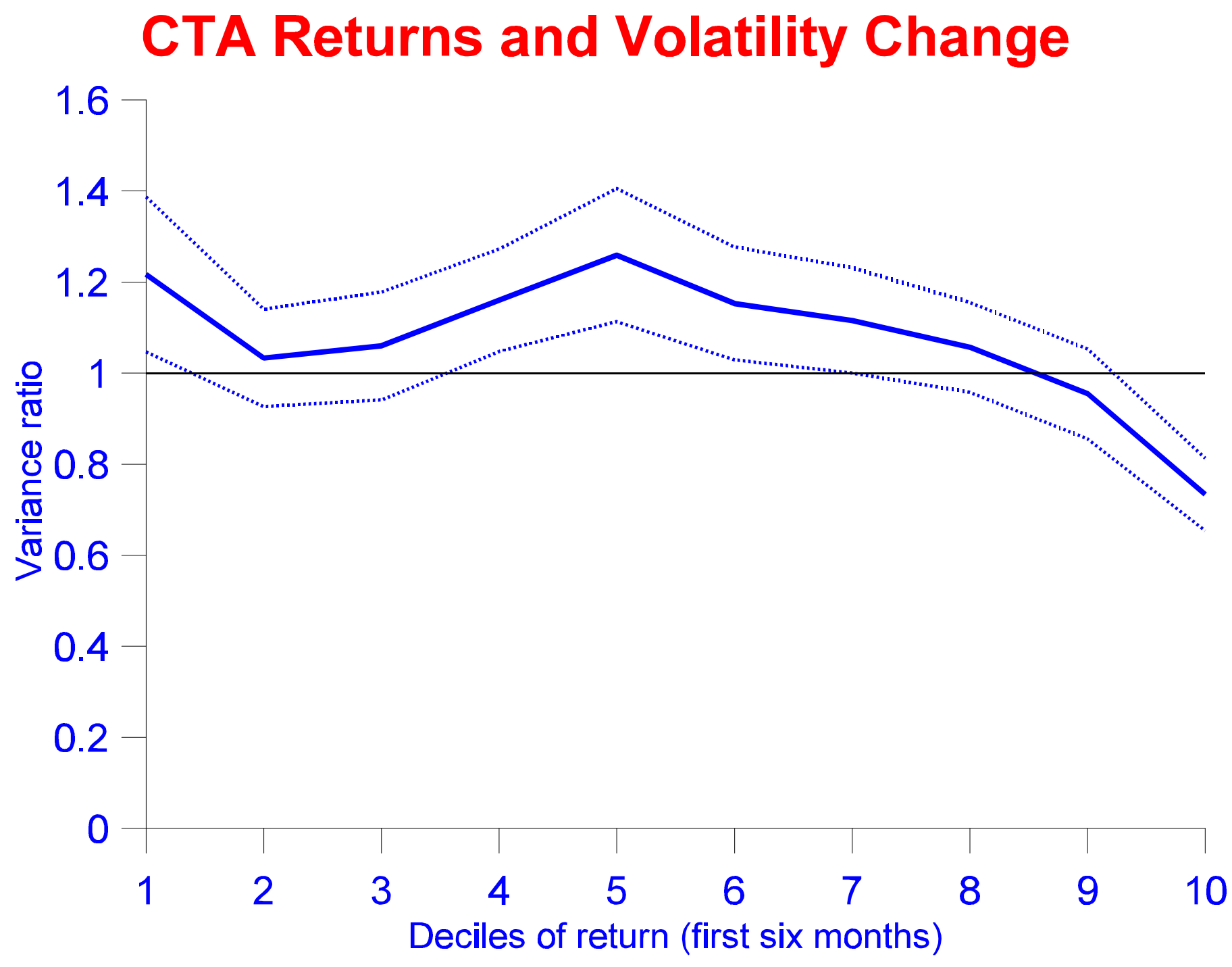

Figure 2

This figure gives the change in volatility for CTAs as a function of relative performance in the first six months. The solid line gives the median volatility ratio for all CTA funds in the sample period 1989-98 with at least one year of complete data, and the dotted lines give the $95 \%$ confidence band for the median. The variance ratio is defined as the ratio of variance of return in excess of style benchmark for the second six month period to the variance of the first six month excess return, and deciles of return are defined relative to realized return measured over the first six months, and excess return is defined relative to style benchmarks. This classification is repeated for each year of our sample 1989-98. 


\section{Hedge Fund Returns and Volatility Change}

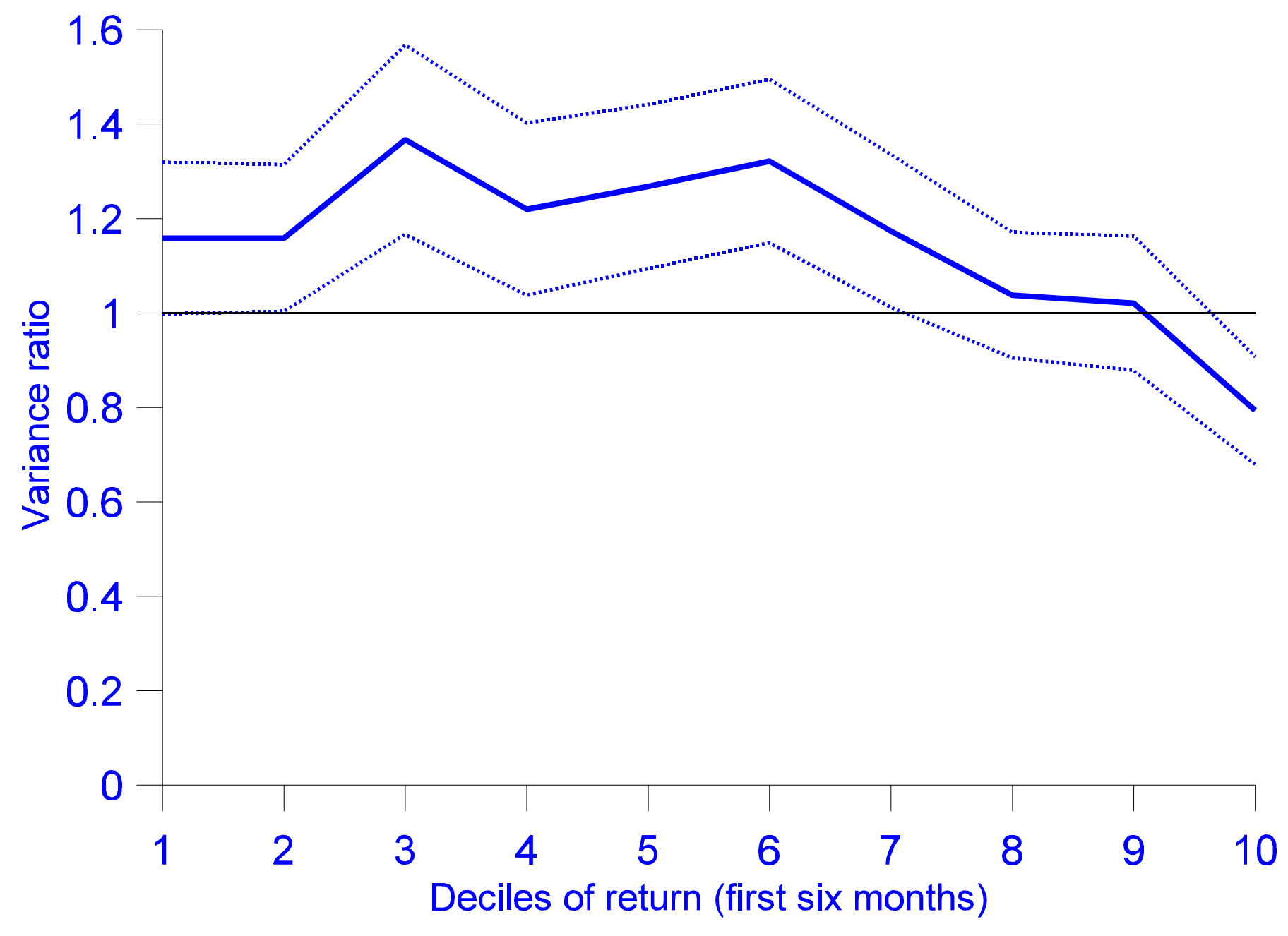

Figure 3

This figure gives the change in volatility for hedge funds as a function of relative performance in the first six months. The solid line gives the median volatility ratio for all hedge funds in the sample period 1989-98 with at least one year of complete data, and the dotted lines give the $95 \%$ confidence band for the median. The variance ratio is defined as the ratio of variance of return in excess of style benchmark for the second six month period to the variance of the first six month excess return, and deciles of return are defined relative to realized return measured over the first six months, and excess return is defined relative to style benchmarks. This classification is repeated for each year of our sample 1989-98. 


\begin{tabular}{|c|c|c|c|c|c|c|c|}
\hline \multicolumn{8}{|c|}{ a. Median Return Benchmark } \\
\hline \multicolumn{3}{|c|}{ Funds with Jan-Jun return less than median } & \multicolumn{2}{|c|}{ Funds with Jan-Jun return greater than median } & \multirow[b]{2}{*}{$\begin{array}{l}\text { Log odds } \\
\quad \text { ratio }\end{array}$} & \multirow[b]{2}{*}{ t-value } & \multirow[b]{2}{*}{$\begin{array}{l}\text { Chi- } \\
\text { square }\end{array}$} \\
\hline Year & Variance ratio low & Variance ratio high & Variance ratio low & Variance ratio high & & & \\
\hline 1989 & 92 & 126 & 126 & 93 & -0.6182 & -3.19 & $10.27 * *$ \\
\hline 1990 & 122 & 156 & 156 & 122 & -0.4917 & -2.88 & $8.32 * *$ \\
\hline 1991 & 149 & 180 & 180 & 149 & -0.3780 & -2.41 & $5.84^{*}$ \\
\hline 1992 & 201 & 212 & 212 & 201 & -0.1066 & -0.77 & 0.59 \\
\hline 1993 & 245 & 283 & 283 & 245 & -0.2884 & -2.34 & $5.47 *$ \\
\hline 1994 & 303 & 322 & 322 & 304 & -0.1183 & -1.05 & 1.09 \\
\hline 1995 & 357 & 363 & 363 & 358 & -0.0305 & -0.29 & 0.08 \\
\hline 1996 & 368 & 428 & 428 & 369 & -0.2994 & -2.98 & $8.89 * *$ \\
\hline 1997 & 442 & 440 & 440 & 443 & 0.0113 & 0.12 & 0.01 \\
\hline 1998 & 411 & 468 & 468 & 411 & -0.2598 & -2.72 & $7.39 * *$ \\
\hline \multirow[t]{2}{*}{$1989-98$} & 2690 & 2978 & 2978 & 2695 & -0.2016 & -5.36 & $28.75^{* *}$ \\
\hline & \multicolumn{7}{|c|}{ b. Highwater Benchmark } \\
\hline & \multicolumn{2}{|c|}{$\begin{array}{l}\text { Funds with Jan-Jun return less than highwater } \\
\text { mark }\end{array}$} & \multicolumn{2}{|c|}{ Funds with Jan-Jun return greater than high water mark } & \multirow{2}{*}{$\begin{array}{l}\text { Log odds } \\
\quad \text { ratio }\end{array}$} & \multirow[b]{2}{*}{ t-value } & \multirow[b]{2}{*}{$\begin{array}{l}\text { Chi- } \\
\text { square }\end{array}$} \\
\hline Year & Variance ratio low & Variance ratio high & Variance ratio low & Variance ratio high & & & \\
\hline 1989 & 41 & 51 & 177 & 168 & -0.2704 & -1.15 & 1.32 \\
\hline 1990 & 52 & 95 & 226 & 183 & -0.8137 & -4.09 & $17.1 * *$ \\
\hline 1991 & 128 & 144 & 201 & 185 & -0.2007 & -1.27 & 1.6 \\
\hline 1992 & 217 & 223 & 196 & 190 & -0.0584 & -0.42 & 0.18 \\
\hline 1993 & 112 & 136 & 416 & 392 & -0.2536 & -1.74 & 3.04 \\
\hline 1994 & 313 & 341 & 312 & 285 & -0.1762 & -1.55 & 2.42 \\
\hline 1995 & 300 & 290 & 420 & 431 & 0.0598 & 0.56 & 0.31 \\
\hline 1996 & 250 & 262 & 546 & 535 & -0.0672 & -0.63 & 0.39 \\
\hline 1997 & 244 & 215 & 638 & 668 & 0.1725 & 1.59 & 2.52 \\
\hline 1998 & 348 & 338 & 531 & 541 & 0.0478 & 0.49 & 0.24 \\
\hline 1989-98 & 2005 & 2095 & 3663 & 3578 & -0.0674 & -1.72 & 2.97 \\
\hline
\end{tabular}

Numbers in the body of the table give the number of funds falling in each classification for all the funds in the sample (results were ver similar broken down into CTAs and hedge funds). Each fund was required to have a complete return history for each calendar year. JanJun return is defined as the total fund return measured over the first six months of each year, and is measured relative to a benchmark of the median fund return over that six month period (Median return benchmark) or highwater mark assuming losses from previous year are carried forward. The variance ratio is defined as the ratio of variance of return in excess of style benchmark for the second six month period to the variance of the first six month excess return. Variance ratio low is defined as a variance ratio less than the median for all funds in the calendar year, and variance ratio high is defined as a variance ratio greater than or equal to the median for all funds. Similar results were obtained defining the variance ratio in terms of realized returns as opposed to excess returns. The log-odds ratio is the log of the ratio of the product of the first and fourth columns to the product of the second and third, and the t-value measures significance of this quantity. The Chi-square numbers represent the $\mathrm{P}^{2}(1)$ statistics from the $2 \times 2$ contingency tables, with values significant at the $5 \%$ level denoted by a single asterisk, and those significant at the $1 \%$ level by a double asterisk. Note that this contingency table statistic is misspecified in this application since the cell counts are not independent. The log odds ratio statistic is robust to this misspecification. 


\section{Table 3: The effect of return, risk and seasoning on fund failure}

a. Probit regression results

CTA results

\begin{tabular}{|c|c|c|c|c|c|c|c|}
\hline Under_quarter & Under_year & Under_2year & $\begin{array}{c}\text { Alpha } \\
\text { (quarter) }\end{array}$ & $\begin{array}{l}\text { Alpha } \\
\text { (year) }\end{array}$ & Age of fund & Time & $\begin{array}{l}\text { Standarc } \\
\text { deviation }\end{array}$ \\
\hline-0.1026 & 0.2602 & 0.3647 & -0.1071 & -0.0129 & -0.0037 & 0.0199 & 0.6001 \\
\hline$(-1.64)$ & $(3.92)$ & $(6.01)$ & $(-3.36)$ & $(-0.52)$ & $(-2.76)$ & $(1.43)$ & $(1.32)$ \\
\hline-0.0869 & 0.3813 & & -0.1037 & -0.0359 & -0.0033 & 0.0179 & 1.0181 \\
\hline$(-1.40)$ & $(6.15)$ & & $(-3.27)$ & $(-1.47)$ & $(-2.50)$ & $(1.30)$ & $(2.31)$ \\
\hline
\end{tabular}

Hedge fund results

Alpha Alpha Standard

Under_quarter Under_year Under_2year (quarter) (year) Age of fund Time deviation

$\begin{array}{rrrrrrrr}-0.0173 & 0.1007 & 0.2544 & -0.0360 & -0.0881 & -0.0061 & 0.1561 & 3.0000 \\ (-0.23) & (1.22) & (3.15) & (-1.05) & (-3.69) & (-3.94) & (7.06) & (3.84) \\ -0.0111 & 0.2050 & & -0.0328 & -0.0965 & -0.0058 & 0.1502 & 3.5003 \\ (-0.15) & (2.76) & & (-0.96) & (-4.08) & (-3.77) & (6.90) & (4.66)\end{array}$

b.Cox semiparametric hazard rate regression results

\section{CTA results}

\begin{tabular}{|c|c|c|c|c|c|c|}
\hline Under_quarter & Under_year & Under_2year & $\begin{array}{c}\text { Alpha } \\
\text { (quarter) }\end{array}$ & $\begin{array}{l}\text { Alpha } \\
\text { (year) }\end{array}$ & Time & $\begin{array}{l}\text { Standard } \\
\text { deviation }\end{array}$ \\
\hline-0.2318 & 0.5553 & 0.6852 & -0.2371 & -0.0255 & 0.0361 & 1.4989 \\
\hline$(-1.70)$ & $(3.88)$ & $(5.30)$ & $(-3.42)$ & $(-0.50)$ & $(1.21)$ & (1.67) \\
\hline-0.0556 & 0.7128 & & -0.1867 & -0.1006 & 0.0367 & 1.6106 \\
\hline$(-0.49)$ & $(6.45)$ & & $(-3.18)$ & $(-2.40)$ & $(1.59)$ & $(2.50)$ \\
\hline
\end{tabular}

Hedge fund results

$\begin{array}{ccccccc}\text { Under_quarter } & \text { Under_year } & \text { Under_2year } & \begin{array}{c}\text { Alpha } \\ \text { (quarter) }\end{array} & \begin{array}{c}\text { Alpha } \\ \text { (year) }\end{array} & \text { Time } & \begin{array}{c}\text { Standard } \\ \text { deviation }\end{array} \\ -0.0080 & 0.2084 & 0.5023 & -0.0802 & -0.1663 & 0.3213 & 5.2930 \\ (-0.05) & (1.15) & (2.92) & (-1.03) & (-3.25) & (6.40) & (3.73) \\ 0.2677 & 0.4181 & & 0.0078 & -0.2065 & 0.3414 & 4.4930 \\ (1.85) & (3.06) & & (0.12) & (-4.81) & (8.45) & (3.84)\end{array}$

This table examines the effect of return, risk and seasoning on the survival of funds applying standard Probit regression and Cox semiparametric hazard rate regression procedures on failure data for CTAs for the period 1989-98, and hedge funds for the period 1994-98. The coefficients in the Probit model are maximum likelihood 
estimates $\hat{\beta}$ for the model $y_{t}{ }^{*}=x_{t} \beta+u_{t}$ where $u_{t}$ is a standard Normal variate and the unobserved indicator variable $y_{t} *>0$ if the fund dies in period $\mathrm{t}$ (for a standard reference, see Greene(1997) Chapter 19) with t-values in parentheses. The coefficients in the Cox semiparametric hazard rate regression model are maximum likelihood estimates $\hat{\beta}$ (t-values in parentheses) for the model $\lambda_{\tau}=\lambda_{0 \tau} e^{x_{i} \beta}{ }_{\text {where }} \lambda_{\tau}$ is the hazard rate, the fraction of funds alive prior to $\tau$ that die at $\tau$. The coefficient $\lambda_{0 \tau}$ is referred to as the baseline hazard rate. This approach makes fewer parametric assumptions about the distribution of the data and does not specify a particular functional form for the role of seasoning in the survival of funds (Lunde, Timmermann and Blake 1999). The variables Under_quarter, Under_year and Under_2year are dummy variables which are one if the fund records a negative holding period return over the prior quarter, year and two year holding periods respectively, Alpha(quarter) and Alpha(year) refer to the ratio of the excess return over the holding period as a fraction of the standard deviation of excess return measured over the prior year multiplied by the square root of the number of months in the holding period, Age of Fund is measured in months, time is a trend term measured in years and Standard Deviation is the standard deviation of excess returns measured over the prior year. 
1.However, this result is consistent with the theory and empirical results in Massa (1997) who finds that relative ranking will tend to dominate as the basis for manager behavior.

2.Ackerman, McEnally and Ravenscraft (1999) also includes data from another vendor, Hedge fund Research and Park (1995) includes data privately collected.

3.Ackermann, McEnally and Ravenscraft(1999) argue that the survival bias is de minimis. However, recent findings (Fung and Hsieh (2000) and Liang (2000)) argue that these results may be an artefact of the particular database used by Ackermann et al.

4.See Brown, Goetzmann, Ibbotson and Ross (1992), Carhart (1997), Hendricks, Patel and Zeckhauser (1997) and Carpenter and Lynch (1997)

5.Eight style benchmarks were computed for this data using the GSC approach described in Brown and Goetzmann (1997), a returns based procedure which like the technique described by Fung and Hsieh (1997), allows styles to be characterized by time-varying factor exposure. Ackerman McEnally and Ravenscraft (1999) define style benchmarks using self-described style characterizations provided to HFR. To the extent that styles share common risk characteristics, this provides some extent of risk adjustment to returns. An earlier version of this paper reports results using the volatility of raw returns, with very similar results. We examined whether results reported in Figures 2 and 3 differ according to style of management. The figures were very similar to those reported here. For each style winners decrease volatility significantly, while losers increase volatility, albeit not significantly. In fact, for two of the eight style classifications considered losers actually reduce volatility.

6.Taking the funds that lost money in the first six months, those that gained more in the second six months than they had lost in the first six months should have experienced a decrease or no change in volatility as the average leverage did not increase. However, the median volatility ratio was actually 1.1561 , contrary to the passive leverage hypothesis. Other funds ought to have experienced a rise in volatility, with the greatest increase occurring for those funds that lost as much in the second period as they had lost in the first period. However, while it is true that the extreme losers did in fact increase volatility, with a median variance ratio of 1.1739 , the other funds actually decreased volatility, with a variance ratio of 0.9331 , contrary to the passive leverage hypothesis. A similar pattern holds for funds that made money in the first six months. Those who made more money by the end of the year than they had made in the first six months and for which, by the passive leverage hypothesis, we would expect to have a substantial reduction in volatility actually increased volatility with a variance ratio of 1.1003 . Funds that lost more than they had won also had an increased volatility with a variance ratio of 1.2578 , while all other winning funds had a volatility ratio of .9731 . In each case, the difference from one is significant at the $5 \%$ level.

7.However, note that this call option argument may actually be consistent with the median manager having a substantial incentive to increase volatility, as the vega is greatest for at the money options. We thank Steve Heston for this observation.

8. While a return less than zero implies that the managers' option is out of the money, it does not follow that a positive return implies that the option is in the money. Some managers are 
evaluated relative to a Tbill return benchmark, and of course managers whose high water mark provision increased on account of a poor previous period return require a substantial positive return before their incentive contract is in the money. It is difficult to model the in the moneyness of the option due to these differences, and the fact that not all high water marks are adjusted on an annual frequency. The second panel of the table assumes the benchmark is increased on an annual basis to reflect past losses. Assuming the benchmark is reset to the current value of the fund each year yields results very similar to those reported in Table 2 , with an overall log-odds ratio of -0.0304 (t-value -.74) and insignificant Chi-square of 0.54 for the period 1989-98

9.Suppose $\alpha_{1}$ and $\alpha_{2}$ are the first and second period performance levels, independent and identically distributed and suppose further that survival requires $\alpha_{1}+\alpha_{2}>c$. Ex post survival conditioning implies that second period variance is increasing in first period performance. Note that $\operatorname{Var}\left[\alpha_{2} \mid \alpha_{1}=a \& \alpha_{1}+\alpha_{2}>c\right]=\operatorname{Var}\left[\alpha_{2} \mid \alpha_{2}>c-a\right]$ is an increasing function of first period performance $a$. We thank Jennifer Carpenter for this observation.

10.The question of survival conditioning is potentially important to cross-sectional performance studies. Brown, Goetzmann, Ibbotson and Ross (1992) point out that survivorship can induce spurious persistence in relative fund returns. Hendricks, Patel and Zeckhauser (1997) discover that survival induces a "J-shape" in performance and variance conditional upon past returns, while Carhart (1997) and Carpenter and Lynch (1999) show how multi-period survival conditioning induces contrasting patterns in persistence tests. 